\title{
EXCISION OF GIANT CELL TUMOR OF TENDON SHEATH WITH BONE INVOLVEMENT BY MEANS OF DOUBLE ACCESS APPROACH: CASE REPORT
}

Marcelo de Pinho Teixeira Alves

\section{ABSTRACT}

Giant cell tumors of the tendon sheath are common lesions and are the second most frequent tumors in the hand, after synovial cysts. They are diagnosed by means of clinical examination and complementary examinations (simple radiography and magnetic resonance). Erosion and invasion of the phalangeal bone affected may be seen on radiological examination. Magnetic resonance may show a "fluorescent or radiant effect" may be observed, caused by the high quantity of hemosiderin inside the tumor. Surgical treatment is the commonest practice, and complete excision is important for avoiding recurrence of the tumor, especially when bone invasion is observed on imaging examinations, which is generally related to greater tumor recurrence. In this paper, a case of a giant cell tumor of the tendon sheath in the middle phalanx of the third finger of a 45 -year-old female patient is presented. This was successfully treated by means of surgery using a double access approach (dorsal and volar).

Keywords - Giant Cell Tumors; Bone and Bones; Radiography; Magnetic Resonance

\section{INTRODUCTION}

Giant-cell tumor of the tendon sheath (GCTTS) is a common lesion and is the second most frequent tumor of the hand, after synovial cysts ${ }^{(1,2)}$. It is a benign tumor with aggressive behavior in some cases, and the best treatment for it is surgical, with wide excision margins ${ }^{(3)}$, while avoiding damage to the adjacent vascular, nerve and tendon structures.

Characteristically, it is a painless nodule that appears on the dorsal or volar side of the finger, generally located proximally to the distal interphalangeal joint $^{(1)}$. Radiographic examination shows that GCTTS generally presents as a soft-tissue mass that may cause a bone impression on the volar face of the adjacent phalanx. GCTTS may sometimes resemble an intraosseous lesion, i.e. cortical or intramedullary, well defined and osteolytic. True bone invasion occurs in around $5 \%$ of the cases ${ }^{(4)}$.

Macroscopically, it is typically a small, encapsulated and lobulated lesion. Microscopically, it consists of hyalinized fibrous tissue, with multinucleated cells, macrophages and xanthomatous cells. It generally presents a varying quantity of hemosiderin ${ }^{(5)}$. The hemosiderin and xanthomatous cells are responsible

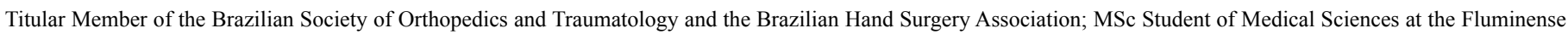
Federal University.

Work performed in the Madureira Traumatological-Orthopedic Clinic, Rio de Janeiro.

Correspondence: Av. Genaro de Carvalho 2597 - 22795-077 - Rio de Janeiro, RJ. Email: marceloptalves@hotmail.com

Work received for publication: February 28, 2010; accepted for publication: August 20, 2010. 
for the gradient differences in magnetic resonance examinations, thus causing a "fluorescent effect" on the images ${ }^{(4)}$.

With regard to surgical treatment, two possibilities are more frequently used: the circumferential incision recommended by Braga Silva et al ${ }^{(1)}$; and the Brunner or mediolateral incisions for volar lesions and longitudinal or transversal incisions for dorsal lesions, recommended by Glowalcki and Weiss ${ }^{(3)}$.

This study presents a case of GCTTS in the region of the middle phalanx of the third finger, with atypical circumferential involvement of the phalanx, thereby causing a bone impression and deformation of the middle phalanx, which was excised by means of a double access approach (dorsal and volar).

\section{CASE REPORT}

The patient was a 45-year-old female with a complaint of swelling on the third finger of her right hand that had been progressing for two years, without pain or neurological complaints.

Physical examination showed a swelling on the third finger in the region of the middle phalanx, without signs of vascular or nerve lesions and without any deficit of flexion-extension of the finger (Figures 1 and 2).

Simple radiological examination of the finger showed morphostructural abnormalities of the middle phalanx, with diaphyseal segmental stenosis and distal subchondral cysts (Figures 3 and 4).

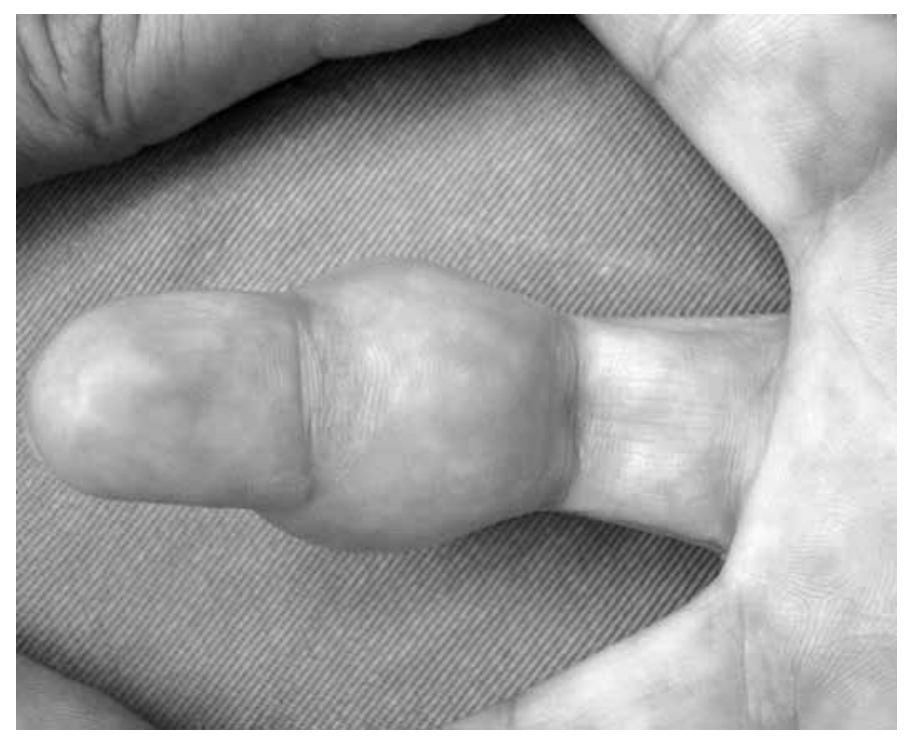

Figure 1 - Volar view of the finger.

Rev Bras Ortop. 2011;46(1):101-6

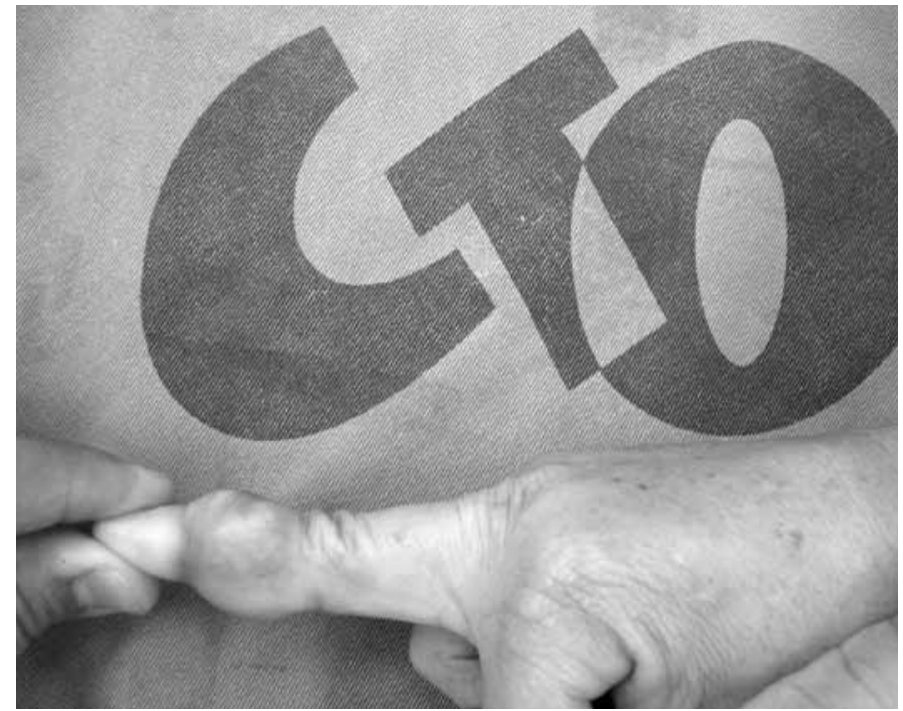

Figure 2 - Lateral view of the finger.

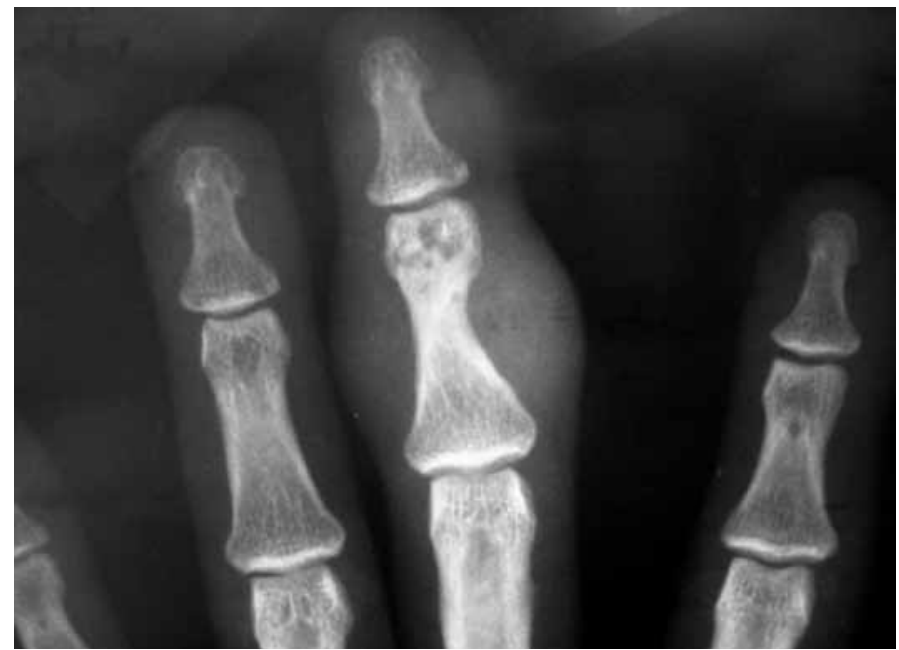

Figure 3 - Anteroposterior radiograph showing stenosis of the diaphysis of the middle phalanx and distal subchondral cysts.

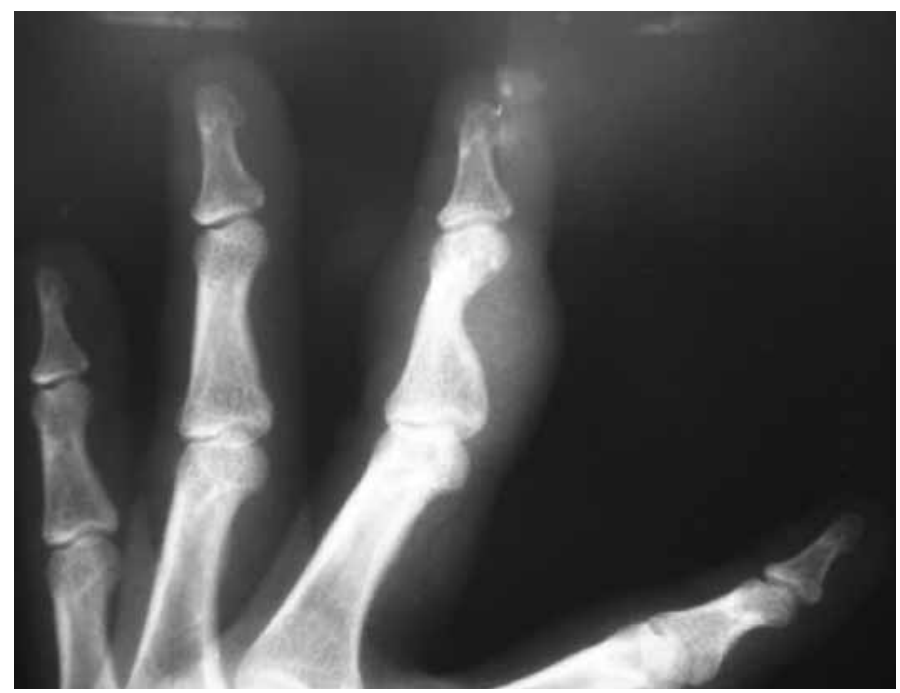

Figure 4 - Oblique radiograph showing the deformity of the middle phalanx. 
The magnetic resonance examination showed an expansive lesion located on the middle phalanx, with its apparent epicenter in the region of the corresponding flexor component. The lesion presented defined limits and a slightly lobulated outline, with dimensions of $1.9 \times 2.1 \times 1.8$ centimeters. It was promoting diaphyseal remodeling of the middle phalanx (Figure 5).

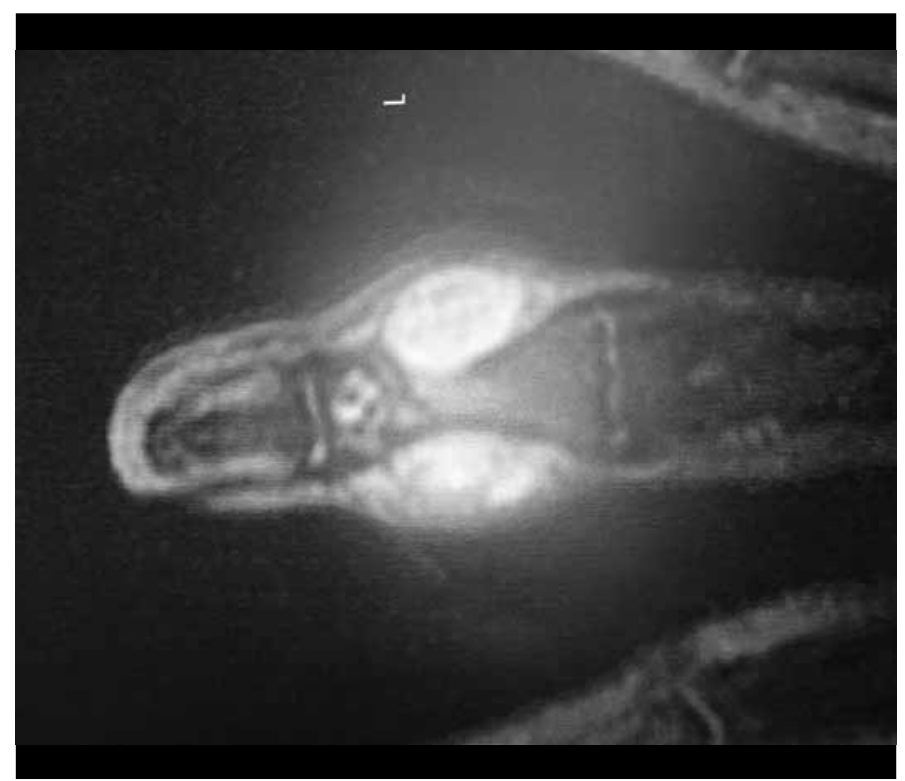

Figure 5 - Magnetic resonance imaging with T2, showing expansive lesion with heterogenous highlighting from the contrast medium.

After signing a free and informed consent statement in order to undergo surgery, the patient underwent surgical excision of the lesion, with a double access approach, under anesthetic block of the brachial plexus and after exsanguination of the arm.

The surgical procedure was started with an S-shaped dorsal access approach above the middle phalanx and extending proximally to the proximal interphalangeal joint (Figure 6).

With careful dissection, it was observed that the lesion involved the middle phalanx, while sparing the extensor tendon complex, but tapering the phalanx (Figure 7).

After releasing the edges of the lesion, while avoiding the vascular and nerve structures, a longitudinal volar incision was made in the middle phalanx (Figure 8 ), and the tumor mass was sectioned longitudinally (Figure 9), so that it could be removed completely via the dorsal approach (Figures 10, 11 and 12).

Subsequently, the specimen was sent for histopa-

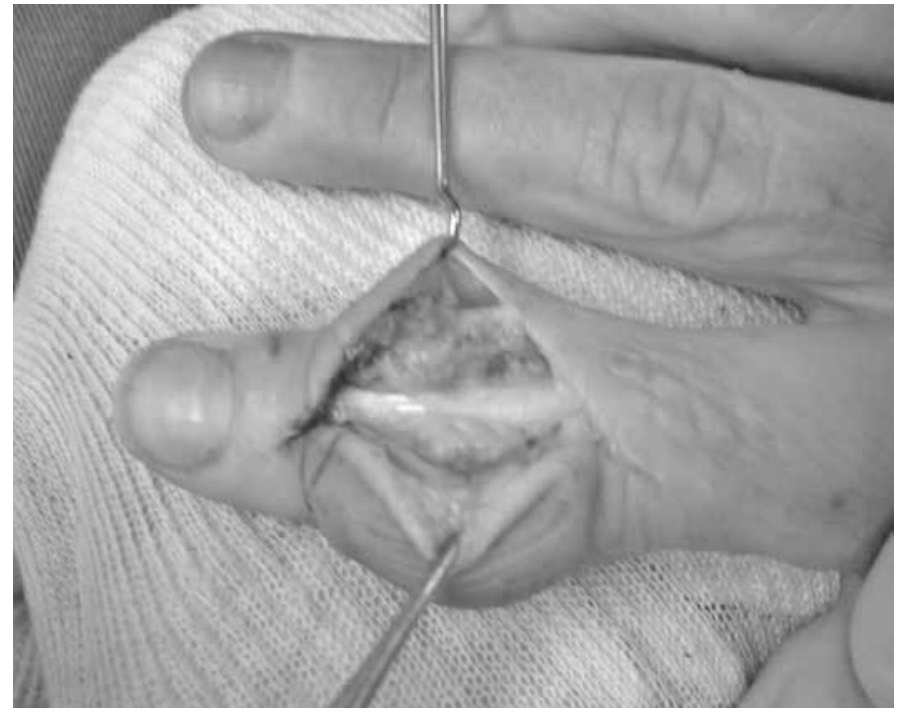

Figure 6 - Dorsal access approach.

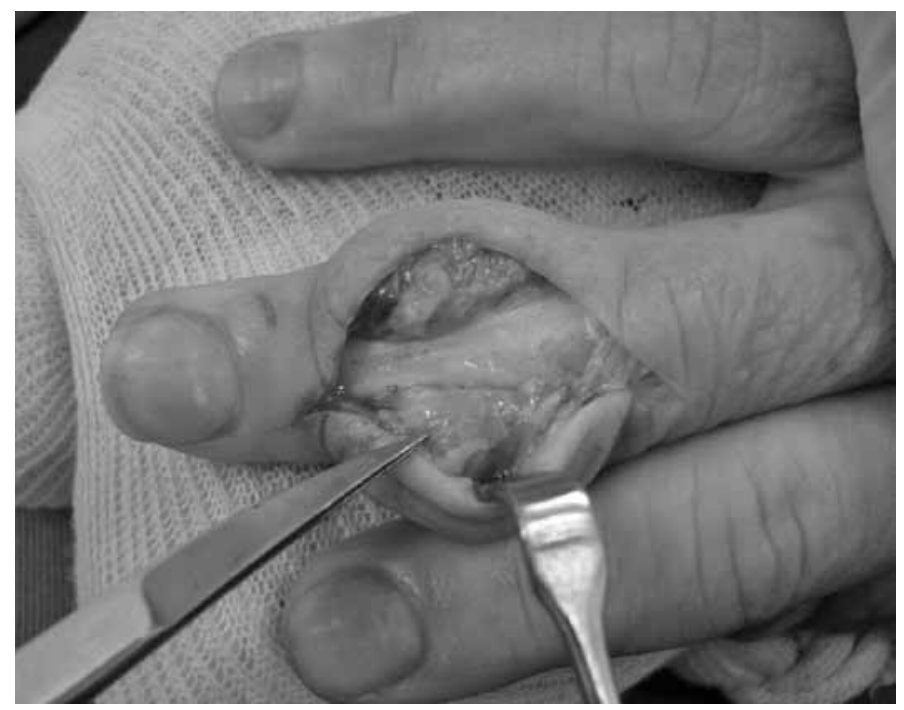

Figure 7 - View of the tumor at the two edges of the extensor complex.

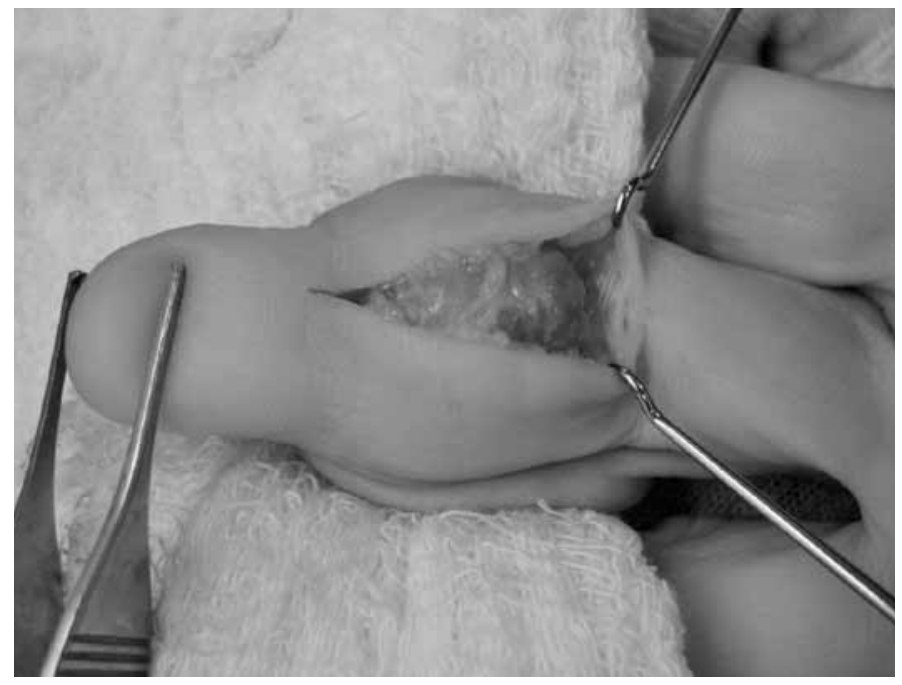

Figure 8 - Volar access approach. 


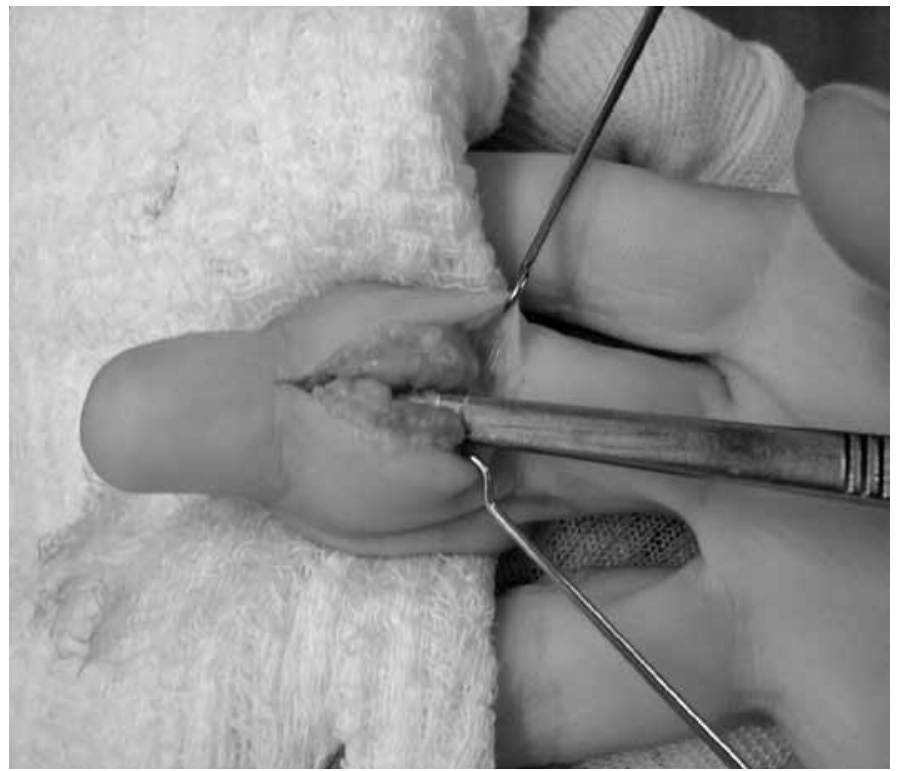

Figure 9-Longitudinal sectioning of the tumor through the volar access.

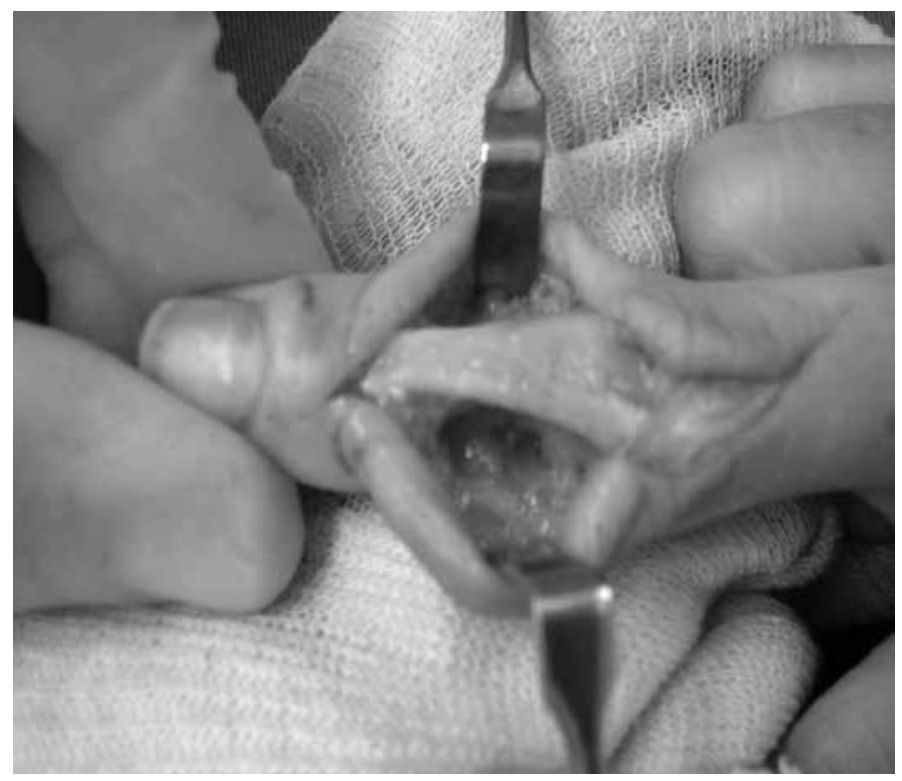

Figure 10 - Longitudinal section of the tumor by the volar approach.

thological examination, which confirmed the diagnosis of GCTTS.

After the surgery, the pneumatic cuff was removed in order to directly observe the integrity of the vascular supply to the finger. The wound was cleaned using $0.9 \%$ physiological solution and simple suturing of the skin was performed using mononylon 4-0 thread (Figure 13). A mildly compressive dressing was applied.

One year after the operation, there has not been any recurrence of the tumor.

Rev Bras Ortop. 2011;46(1):101-6

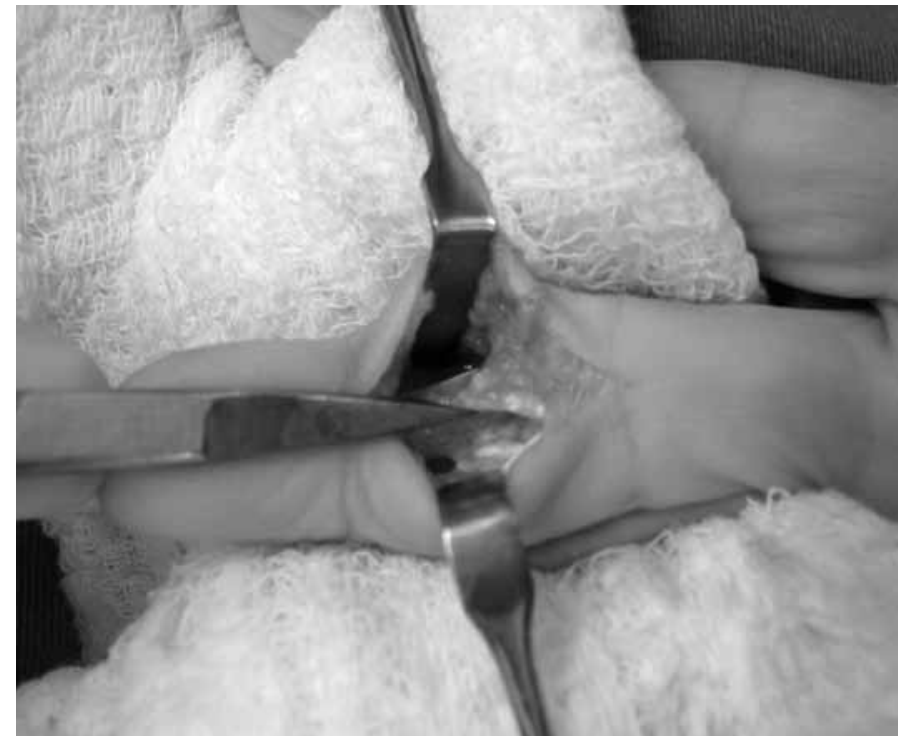

Figure 11 - Volar view after excision, indicating the point of origin of the tumor.

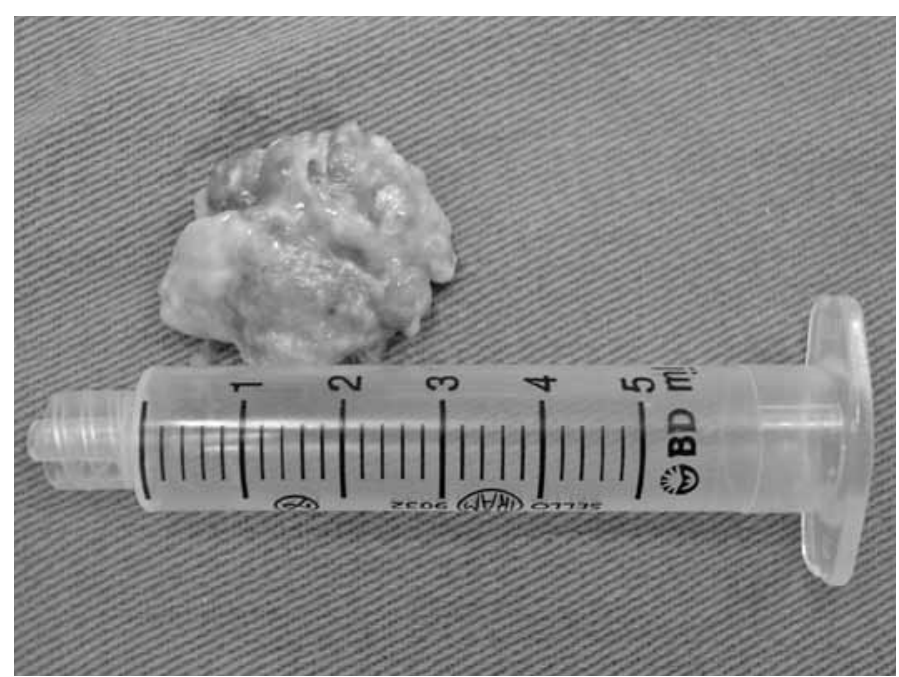

Figure 12 - Photograph showing the size of the tumor after excision.

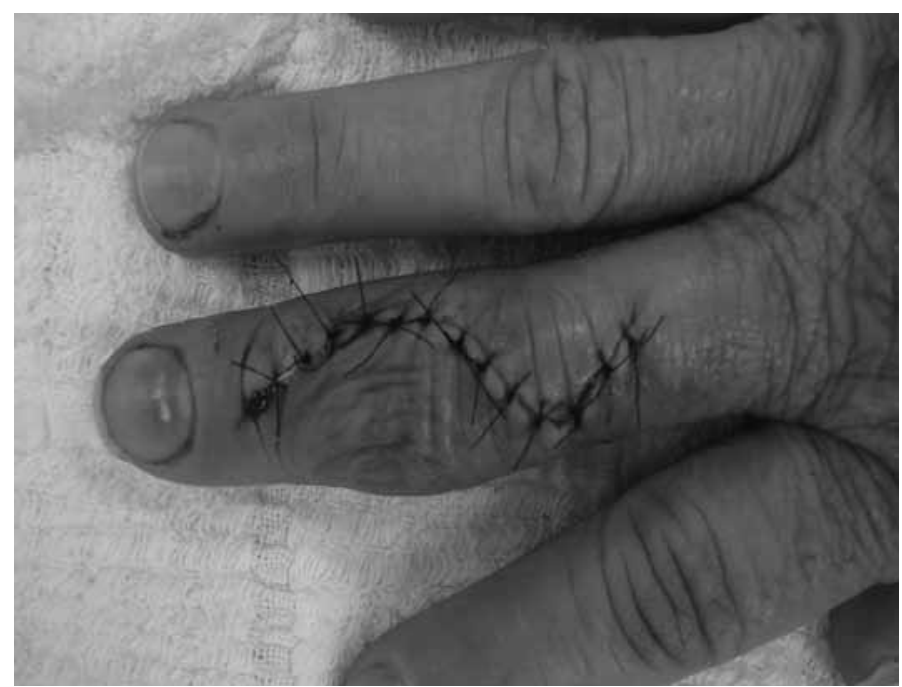

Figure 13 - Photograph evidencing the tumor size after excision. 


\section{DISCUSSION}

GCTTS occurs most commonly in the hand and fingers, typically affecting female patients in the age range from 30 to 50 years. It is most frequent in the second and third fingers, close to the distal interphalangeal joint, with a volar location in around two thirds of the cases ${ }^{(1,6)}$.

The bone deformation in the middle phalanx of the case presented here illustrates the need to make a differential diagnosis between GCTTS and other lesions that cause bone impression and erosion, such as cortical defects and cystic lesions in the fingers ${ }^{(4)}$. The mechanism for bone invasion has still not been demonstrated, but it is believed that GCTTS reaches the medullary canal through the vascular foramens of the bone $\mathrm{e}^{(7)}$.

Magnetic resonance imaging (MRI) is very valuable for preoperative planning ${ }^{(8)}$. It shows the morphological characteristics of the tumor, comprising a well defined rounded, oval or multilobular mass of soft tissue that is either eccentric or surrounds the tendon sheath ${ }^{(4)}$. Bone invasion is also well demonstrated by MRI, as was seen in the present case.

In this case, the diagnosis of GCTTS was in agreement with the literature regarding the findings of sex, age and finger affected ${ }^{(6)}$. More specifically, the findings agreed with the descriptions provided by Braga Silva et $\mathrm{al}^{(1)}$, who observed that most of the lesions operated were dorsal and volar, and that they affected the middle phalanx.

Surgical treatment consisting of complete excision of the tumor while preserving the adjacent structures is the recommended approach. The surgeon needs to take into consideration that the tumor should be completely and aggressively removed, while the normal tissue has to be preserved to enable functioning and recovery ${ }^{(8)}$. The incisions planned by Glowalcki and Weiss ${ }^{(3)}$ and by Braga Silva et $\mathrm{al}^{(1)}$ are options for resection of GCTTS, with excellent exposure of the tumor. However, in the present case, it was decided to excise the tumor using a double access approach (dorsal and volar), because of the characteristics demonstrated by MRI, which showed circumferential involvement of the finger. This approach allowed complete resection, while avoiding compromising the vascular supply at the distal extremity of the finger.

Despite the high recurrence rate reported in the literature $^{(1,9)}$, in up to $45 \%$ of the cases ${ }^{(10)}$, there was no recurrence within the first year of postoperative follow-up in the case of this patient. Tumor recurrence is generally more frequent when bone invasion occurs $^{(8,11)}$. In the study by Reilly ${ }^{(11)}$ et al, bone involvement with erosion was found in $9 \%$ of the patients in the initial operation, and in $26 \%$ of the cases with recurrence. The length of the postoperative follow-up in the present case is still short, given that according to Williams et $\mathrm{al}^{(10)}$, the recurrence rate that they found five years after surgery was $13 \%$. In their study, they generally found cases of recurrence three years after the surgery, on average. These authors affirmed that greater risk of recurrence could be predicted based the characteristic of involvement of the joint capsule, extensor tendon and flexor tendon. Cases in which any or all of these structures were affected were associated with a recurrence rate of $32 \%$. However, in the case presented in the present study, none of these structures was involved, which may lead to a lower chance of recurrence.

GCTTS occurs frequently in the hand, especially affecting the phalanges of the fingers. It is benign but aggressive, and surgical treatment is mainly indicated. Such treatment needs to be aggressive but, at the same time, it needs to preserve as much of the normal tissues, so that the finger does not become functionally compromised.

In addition to a good anamnesis and physical examination, a good radiological examination to demonstrate possible bone involvement and MRI examination (when available) are fundamental for the clinical and imaging diagnosis, thus enabling predictions regarding any predisposition towards lesion recurrence.

In the case presented, surgical treatment of GCTTS by means of a double access approach was appropriate for complete resection of the tumor. Up to the present time, there has not been any recurrence in this case, despite the high rate found in the literature. Longer postoperative follow-up has thus become a necessity for this patient. 


\section{REFERENCES}

1. Braga Silva J, Calcagnotto GN, Scolari J, Fridman M. Tumor de células gigantes da bainha tendinosa no nível dos dedos: exérese através da incisão circunferencial. Rev Bras Ortop. 2002;37(4):129-32.

2. Darwish FM, Haddad WH. Giant cell tumour of tendon sheath: experience with 52 cases. Singapore Med J. 2008;49(11):879-82.

3. Glowacki KA, Weiss AP. Giant cell tumors of tendon sheath. Hand Clin. 1995;11(2):245-53.

4. Walsh EF, Mechrefe A, Akelman E, Schiller AL. Giant cell tumor of tendon sheath. Am J Orthop (Belle Mead NJ). 2005;34(3):116-21.

5. Nahra ME, Bucchieri JS. Ganglion cysts and other tumor related conditions of the hand and wrist. Hand Clin. 2004;20(3):249-60.

6. Gibbons CL, Khwaja HA, Cole AS, Cooke PH, Athanasou NA. Giant-cell tumour of the tendon sheath in the foot and ankle. J Bone Joint Surg Br. 2002;84(7):1000-3.
7. De Schepper AM, Hogendoorn PC, Bloem JL. Giant cell tumors of the tendon sheath may present radiologically as intrinsic osseous lesions. Eur Radiol. 2007;17(2):499-502.

8. Uriburu IJ, Levy VD. Intraosseous growth of giant cell tumors of the tendon sheath (localized nodular tenosynovitis) of the digits: report of 15 cases. J Hand Surg Am. 1998;23(4):732-6.

9. Llauger J, Palmer J, Rosón N, Cremades R, Bagué S. Pigmented villonodular synovitis and giant cell tumors of the tendon sheath: radiologic and pathologic features. AJR Am J Roentgenol. 1999;172(4):1087-91.

10. Williams J, Hodari A, Janevski P, Siddiqui A. Recurrence of giant cell tumors in the hand: a prospective study. J Hand Surg Am. 2010;35(3):451-6.

11. Reilly KE, Stern PJ, Dale JA. Recurrent giant cell tumors of the tendon sheath. J Hand Surg Am. 1999;24(6):1298-302. 